\title{
HORMONE RECEPTOR STATUS OF BREAST CANCER IN NORTHERN REGION OF INDIA- A STUDY
}

\author{
Arundhati ${ }^{1}$, Anupama ${ }^{2}$ \\ ${ }^{1}$ Consultant Pathologist, Mahavir Cancer Sansthan and Research Institute, Patna. \\ ${ }^{2}$ Senior Resident, Department of Obstetrics and Gynaecology, Patna Medical College and Hospital, Patna.
}

\section{ABSTRACT}

\section{BACKGROUND}

The aim of this study is to evaluate the age and sex wise incidence of breast carcinoma in this particular region of India and expression of hormone receptor in the same population.

\section{MATERIALS AND METHODS}

This study is an observational study, which includes 1446 cases of breast cancer of which 1423 were female and 23 were male. In this study, patients were analysed on the basis of age of occurrence, sex and hormone receptor expression, evaluated immunohistochemically.

\begin{abstract}
RESULTS
Age of occurrence and hormone receptor expression, both are lower in the studied population as compared to western population. In males, breast cancer is rare and constituted just 1.6\%. In our study, the overall Oestrogen Receptor (ER) positivity in female breast cancer cases is found to be $44.0 \%$ and Progesterone Receptor (PR) positivity is $45 \%$. Our study also found that ER negative/PR positive breast cancer as a definite subgroup constituting $9.8 \%$ of all the four groups based on hormone receptor expression.
\end{abstract}

\section{CONCLUSION}

We conclude that female breast cancer cases from this northern region of India do show lower hormone receptor expression as compared to comparable population from western world. Our study also acknowledges ER negative and PR positive breast cancer subgroup as a definite entity.

\section{KEYWORDS}

Breast Cancer, Oestrogen Receptor, Progesterone Receptor, Immunohistochemistry.

HOW TO CITE THIS ARTICLE: Arundhati, Anupama. Hormone receptor status of breast cancer in northern region of India- A study. J. Evolution Med. Dent. Sci. 2017;6(29):2362-2365, DOI: 10.14260/Jemds/2017/509

\section{BACKGROUND}

Cancer is the second most common cause of death worldwide next only to cardiovascular disease. Amongst the type of cancers, breast cancer is the most common malignant tumour constituting $21 \%$ of all tumours.[1] It is the most common cancer of women in urban India. [2] According to urban cancer registry in India, it accounts for around $30 \%$ of all cancers in females.[3] In India, breast cancer has overtaken cervical cancer in many regions, which was the most frequent type of cancer a decade ago. $[4]$

Conventionally many risk factors have been associated with breast cancer, but age is the single most important risk factor.[5] Other factors include lower age of menarche $(<12$ Years), higher age for menopause ( $>55$ Years), higher age for first full-term pregnancy, lesser duration of breast-feeding, benign breast disease, genetic factors, obesity, environmental and hormonal factor[6]; however, in $50 \%$ of women the risk factors are not detected.[7] Breast cancer is a clonal disease. It may occur due to germline, genetic or acquired mutation in PTEN, BRCA-1, BRCA-2 and p53 genes.[6]

Financial or Other, Competing Interest: None.

Submission 24-02-2017, Peer Review 27-03-2017,

Acceptance 04-04-2016, Published 10-04-2017.

Corresponding Author:

Dr. Arundhati,

Consultant Pathologist,

Mahavir Cancer Sansthan,

Patna, Bihar.

E-mail: ashok_74_kumar@yahoo.co.in

DOI: $10.14260 /$ jemds/2017/509
Normal breast tissue is oestrogen dependent. Primary or metastatic breast cancer may retain this phenotype. It is one of the hormone dependent tumours, the hormones are predominantly secreted by ovaries. That is why, women without functioning ovaries and not receiving oestrogen supplementation have lesser chances of developing it and those with cancer may respond to endocrine therapy, if found positive for hormone receptors.[6]

Immunohistochemistry has diagnostic and theranostic role in cases of breast cancer. Hormone receptors are routinely measured as it could impact treatment decisions. Gone are the days when patients were treated empirically with tamoxifen. Oestrogen receptor positive breast cancers respond to hormonal therapy in 30\% cases, both oestrogen and progesterone receptor positivity increases the likelihood of response in $70 \%$ cases, whereas if both are negative the response rate is reduced to just $5 \%$. In hormonal therapy even PR positivity implies a functioning ER pathway.[8]

Clinical trials have also shown that the survival advantage for women with hormone receptor-positive tumours is further enhanced by treatment with adjuvant hormonal and/or chemotherapeutic regimens.[9] Human epidermal receptor-2/neu (HER-2/neu) gene amplification occurs in 20$30 \%$ of breast cancers and it is associated with poor prognosis, lower response to hormone therapy and chemotherapy. The present study was planned keeping in mind to establish the hormone receptor status pattern and its correlation with age and sex in a north Indian population of patients presenting in a tertiary care cancer hospital of Bihar. 


\section{MATERIALS AND METHODS}

\section{Study Design}

The study was carried out in Mahavir Cancer Sansthan and Research Centre which is a tertiary care cancer hospital of Bihar. A total of 1446 cases of epithelial malignancy of breast were included, of which 1423 were female and 23 were male. Rare malignancies presenting in breast like sarcomas and lymphomas were not included. The cases were selected randomly, who presented in our hospital from August 2009 to March 2016. The identity of the cases was kept secret and ethical permission was taken from Institutional Ethical Committee, Mahavir Cancer Sansthan and Research Centre.

\section{Methodology for Immunohistochemistry}

All the cases were immunohistochemically evaluated for oestrogen and progesterone hormone receptor status, (ER and PR), expression using standard HRP Detection system method. Pressure cooking/microwave method was used for antigen retrieval. Adequate tissue fixation in $10 \%$ neutral buffered formalin for 6-48 hours was ensured. Paraffin sections (3-4 $\mu \mathrm{m}$ thick) with maximum invasive tumour component were selected for IHC. The antibodies used for ER and PR were monoclonal rabbit anti-Human Oestrogen Receptor, BIOGENEX (Clone ID5 and EP1; prediluted) and monoclonal, mouse anti-Human Progesterone Receptor, BIOGENEX (Clone PR 88; prediluted) respectively. The scores for ER and PR were calculated using the Allred Scoring method.

All the tests were interpreted with negative and positive controls. Staining of the nuclei of the normal ductal epithelium was used as the internal control for ER and PR staining while interpreting the slides.

ER or PR was considered positive if finding of more than $1 \%$ tumour cell nuclei are immunoreactive. Negative for ER or PR if finding of less than $1 \%$ of tumour cell nuclei are immunoreactive.

\section{Statistical Analysis}

Analysis was done by using statistical software GraphPad Prism and data was expressed as mean \pm SEM and percentages.

\section{RESULTS}

Out of the 1446 cases of breast cancer that were studied, 1423 were female and 23 were male. The ages of the study subjects ranged from 18 to 83 years. The median age was 50 years. Mean \pm Standard Error of Mean (SEM) age of male breast cancer patients is $60.96 \pm 2.46$ years whereas the Mean \pm SEM age of female breast cancer patients is $47.56 \pm$ 0.29 years. Total number of ER and PR positive female patients is 505 whereas ER and PR positive male patients is 19. The number of ER positive and PR negative female patients is 123 whereas male patients were 3 . There was no male patient in the category of ER negative and PR positive tumour.

In comparison of number of overall patients with ER positive and PR positive tumours with ER negative and PR negative tumours is $36.24 \%$ as compared to $45.23 \%$ (Figure 1 ).

Patients of less than 35 years of breast carcinoma are considered very young and when these patients were compared to higher age group with regards of ER positive and PR positive number of tumours is $5.27 \%$ as compared to $30.22 \%$. In comparison of same group of patients, the number of ER positive and PR negative patients is 1.12\% and $7.52 \%$ respectively. When ER negative and PR positive number of tumours was compared in the above mentioned population groups, it was $1.34 \%$ in patients of less than 35 years of age of breast carcinoma as compared to $8.64 \%$ in higher age group. On analysing ER negative and PR negative tumours, it was found that in below 35 years of population of carcinoma breast these patterns of non-expression of hormone receptors were relatively and significantly higher and for this population it was $7.66 \%$ whereas in higher age group population it was $38.23 \%$.

ER positivity of male breast carcinoma was $96 \%$ (Figure 2) which is quite high as compared to $44 \%$ of the same on female comparable population (Figure -3) leading us to conclude that breast carcinoma is more hormone dependent in males as compared to females. Dual hormone receptor negative tumours constitute $46 \%$ of the cases of female breast cancer (Figure 4). In a developing country like India and state like Bihar where finance and resources are major constraints, patients knowing the costly therapeutic option based on HER-2 receptor expression rarely opt for its testing. In patients below 35 years this proportion is still higher constituting to $50 \%$ (Figure 5).
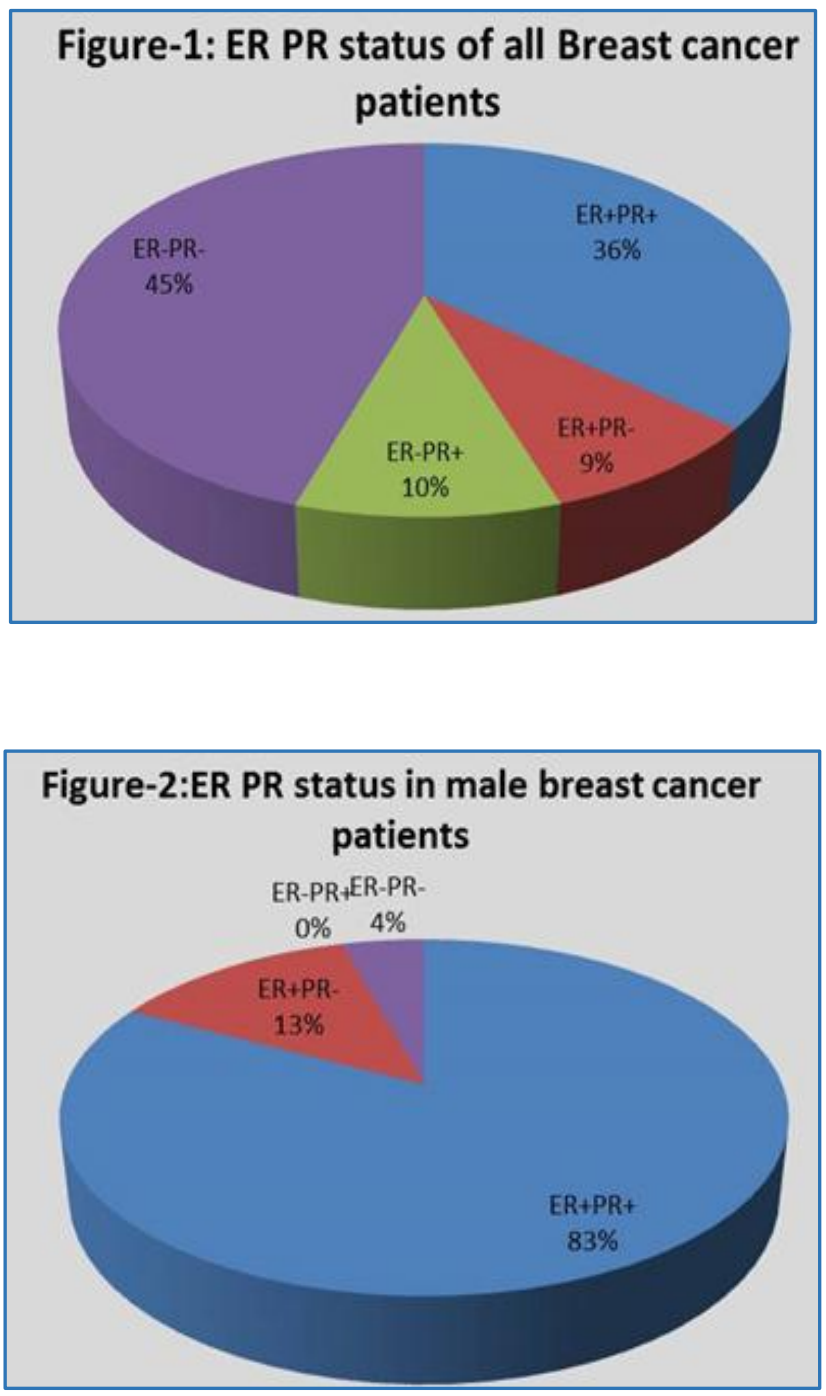

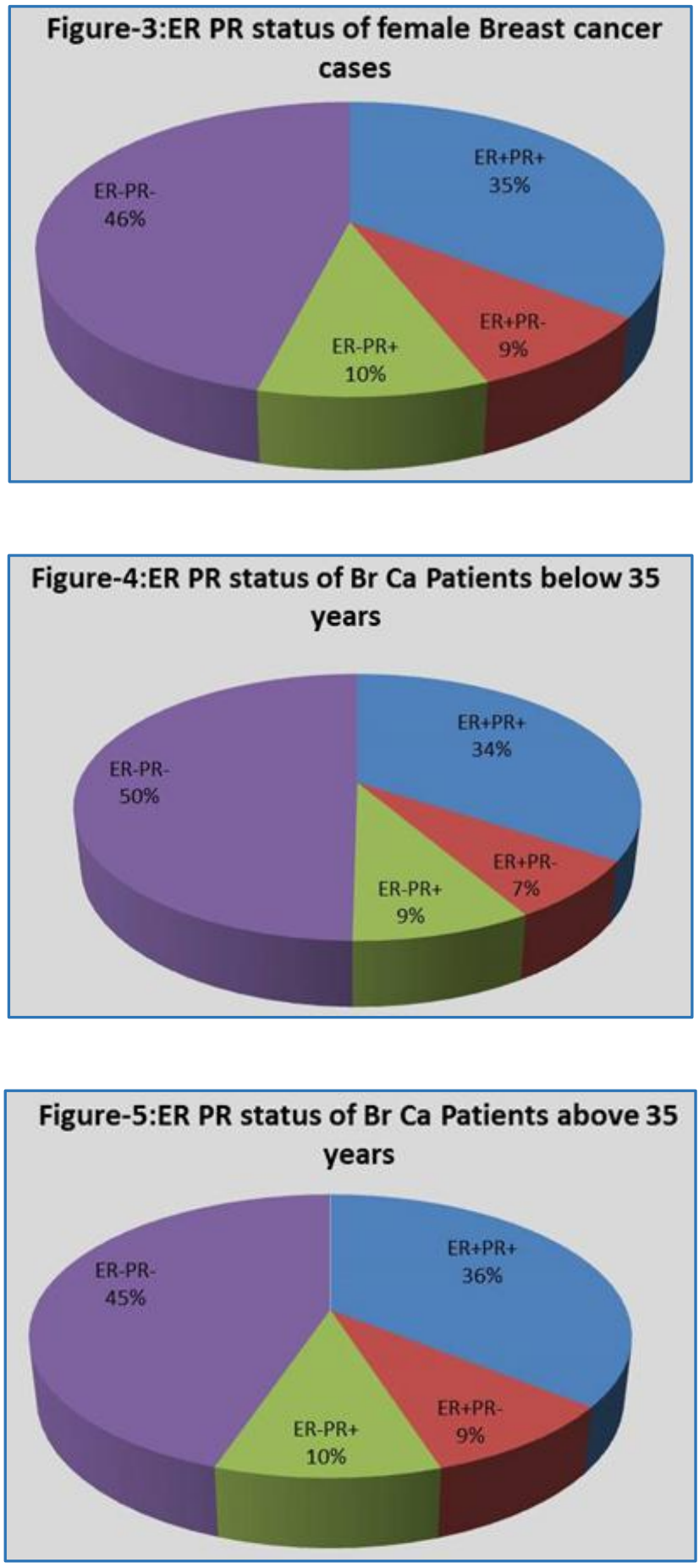

\section{DISCUSSION}

Amongst all the cancers presenting in our hospital, breast cancer constitutes the most commonly presented variety of cancer among female patients; however in males, breast cancer is rare and constituted $1.6 \%$, which is slightly higher as compared to other studies, in which it accounts for only $0.7 \%$ in the study of Jemal et al,[10] $<1 \%$ according to Giordano et al,[11] and 1\% in Fentiman et al study[12] of all breast cancer diagnoses. In Korea, Male Breast Cancer constitutes $0.4-0.6 \%$ of all breast cancers.[13] In Europe, approximately $1 \%$ of all Breast Cancer occur in males, but the incidence is pretty higher in sub-Saharan Africa with $15 \%$. This difference in propensity for development of male breast cancer in different geographical regions may be due to genetic, hormonal, dietary or environmental factors. ${ }^{[14]}$
In U.S. the mean age at diagnosis for men with breast cancer is 67 years, which is 5 years older than the average age at diagnosis for women, which is close to our finding of mean age of $60.96 \pm 2.46$ years so just like female breast cancer cases, in male breast cancers also age of occurrence of disease is low in India as compared to western population. Hormone receptor expression in male breast cancer cases is quite high (96\%) just like most of the studies reporting from different parts of world.[15] Median age at diagnosis in Korea is 56 Years,[16] but in India the median age at diagnosis was 57 years (range 45-75).[17]

Mir et al found in their study that $12 \%$ breast cancers occur in women between 20 - 34 years, ${ }^{[18]}$ similar to our study in which we found $15 \%$ breast cancers occur in women between 18-35 years. Both ER and PR negative tumours were highest $(50 \%)$ in women of below 35 years.

Like most other studies from India, our study also found the largest number of cases falling in 41 - 50 years age group; however, it was followed by 31 - 40 years unlike most other studies. Most other studies have found $51-60$ years as the second most common decade for breast cancer.[19]

In our study, the overall ER positivity in female breast cancer cases is found to be $44.0 \%$, which lies in the range reported by different Indian institutes, however, pretty low as compared to the reportings form western world.[20] ER negative and PR positive tumours are relatively rare cancers based on hormone receptor expression which accounts for just $1-4 \%{ }^{[21]}$ of all cases according to Navani et al and was found to be $5.3 \%[22]$ in the study of Vettuparambil et al. Studies done in India and on Indian emigrants have found ER positivity in Indian women in the range of $34.5 \%$ to $55.1 \%$.[23] The average ER positivity for white women in the US is $77 \%$. PR positivity from our study in female breast cancer cases is $45 \%$ which is close to percentage of ER value and comparable to other studies reported from different parts of India with PR expression of $33.3 \%,{ }^{[24]} 41.5 \%,[25]$ and $42 \%$.[26] Though white women in US showed 55\% PR positivity.

Though De Maeyer et al have completely defied ER negative and PR positive tumours in their study after repeating the test process and putting the threshold for ER positivity as any nuclear staining of invasive tumour cells. ${ }^{[27]}$ Shen et al in their study analysed 5374 consecutive breast cancer cases and concluded ER negative/PR positive as a definite subset group of breast cancer cases constituting 2.3\% of the total number of cases.[28] Zhu et al in their study at relapse of primary to metastatic lesion in breast carcinoma found that the rate of gain of ER and PR positivity were 10.9 and $13.5 \%$ respectively; the rates of loss of ER and PR positivity were 23.3 and $24.9 \%$. ER and PR receptors are codependent.[29] The hormone receptors crosstalk with epidermal growth factor receptor and may silence each other. [30] Ethnic group, geographical area, genetic drift are the factors which may influence the hormone receptor expression. In our study, ER negative and PR positive tumours constitute $9.83 \%$ which is quite high. Shen et al in their study found no survival advantage between ER positive/PR negative and ER negative/PR positive tumours. Both of them demonstrated similar response rate to endocrine therapy which is poorer than ER positive/PR positive. 


\section{CONCLUSION}

Thus, our study is a large study and it gives a sneak peek in the incidence of breast carcinoma in this particular region of India and its sex wise distribution. The study also focuses on hormone receptor distribution in male breast cancer patients, young female breast cancer patients of $<35$ years and in female breast cancer patients of $>35$ years. We know that hormone receptor expression decides the prognosis and therapeutic options. Our study throws light on the pattern of hormone receptor expression in these geographic areas, ethnic race and in different age groups. Cases of ER negative and PR positive breast cancer are significantly higher in this region as compared to other studies conducted worldwide. Above facts when considered together can help in developing and deciding a personalised treatment plan and followup in the people of this region.

\section{REFERENCES}

[1] World Health Organization. The global burden of disease: 2004. Accessed June 8, 2015. http://www.who.int/healthinfo/global_burden_diseas e/2004_report_update/en/.

[2] Singhai R, Patil VW, Patil AV. Status of HER-2/neu receptors and Ki-67 in breast cancer of Indian women. Int J App Basic Med Res 2011;1(1):15-9.

[3] Manoharan N, Tyagi BB, Raina V. Cancer incidences in rural Delhi--2004-05. Asian Pac J Cancer Prev 2010;11(1):73-7.

[4] Murthy NS, Chaudhry K, Nadayil D, et al. Changing trends in incidence of breast cancer: Indian scenario. Indian J Cancer 2009;46(1):73-4.

[5] Current medical diagnosis and treatment. 54th edn. San Francisco: McGraw Hill, 2015:pp 720.

[6] Harrison's principle of internal medicine. 19th edn. U.S.A.: McGraw Hill, 2015:523-4.

[7] Leake R. Comment. Breast 2000;9:270.

[8] Fletcher CDM. Diagnostic histopathology of tumors. $3^{\text {rd }}$ edn. Philadelphia: Churchill Livingstone, 2007.

[9] Dunnwald LK, Rossing MA, Li CI. Hormone receptor status, tumor characteristics, and prognosis: a prospective cohort of breast cancer patients. Breast Cancer Res 2007;9(1):R6.

[10] Jemal A, Tiwari RC, Murray T, et al. Cancer statistics, 2004. CA Cancer J Clin 2004;54(1):8-29.

[11] Giordano SH, Buzdar AU, Hortobagyi GN. Breast cancer in men. Ann Intern Med 2002;137(8):678-87.

[12] Fentiman IS, Fourquet A, Hortobagyi GN. Male breast cancer. Lancet 2006;367(9510):595-604.

[13] The Korean Breast Cancer Society. Nationwide Korean breast cancer data of 2004 using breast cancer registration program [In Korean]. J Breast Cancer 2006;9(2):151-61.

[14] Carlsson G, Hafström L, Jönsson PE. Male breast cancer. Clin Oncol 1981;7:149-55.

[15] Giordano SH, Cohen DS, Buzdar AU, et al. Breast carcinoma in men: a population-based study. Cancer 2004;101(1):51-7.
[16] Park S, Kim JH, Koo J, et al. Clinicopathological characteristics of male breast cancer. Yonsei Med J 2008;49(6):978-86.

[17] Chikaraddi SB, Krishnappa R, Deshmane V. Male breast cancer in Indian patients: is it the same? Indian J Cancer 2012;49(3):272-6.

[18] Mir R, Singh VP. Breast cancer in young women and its impact on reproductive function. Apollo Medicine 2009;6(3):200-8.

[19] Rajan G, Culas TB, Jayalakshmy PS. Estrogen and progesterone receptor status in breast cancer: a crosssectional study of 450 women in Kerala, South India. World Journal of Surgical Oncology 2014;12:120.

[20] SEER Stat database. http://seer.cancer.gov/statfacts/ html/breast.html.

[21] Kaul R, Sharma J, Minhas SS, et al. Hormone receptor status of breast cancer in the Himalayan region of northern India. Indian J Surg 2011;73(1):9-12.

[22] Dey S, Boffetta P, Mathews A, et al. Risk factors according to estrogen receptor status of breast cancer patients in Trivandrum, South India. Int J Cancer 2009;125(7):1663-70.

[23] Yip CH, Pathy NB, Uiterwaal CS, et al. Factors affecting estrogen receptor status in a multiracial Asian country: an analysis of 3557 cases. Breast 2011;20(Suppl 2):S60-4.

[24] Kuraparthy S, Reddy KM, Yadagiri LA, et al. Epidemiology and patterns of care for invasive breast carcinoma at a community hospital in Southern India. World J Surg Oncol 2007;5:56.

[25] Rajan G, Culas TB, Jayalakshmy PS. Estrogen and progesterone receptor status in breast cancer: a crosssectional study of 450 women in Kerala, South India. World J Surg Oncol 2014;12:120.

[26] Shet T, Agrawal A, Nadkarni M, et al. Hormone receptors over the last 8 years in a cancer referral center in India: what was and what is? Indian J Pathol Microbiol 2009;52(2):171-4.

[27] De Maeyer L, Van Limbergen E, De Nys K, et al. Does estrogen receptor negative/progesterone receptor positive breast carcinoma exist? J Clin Oncol 2008;26(2):335-6.

[28] Shen T, Brandwein-Gensler M, Hameed 0 , et al. Characterization of estrogen receptornegative/progesterone receptor-positive breast cancer. Hum Pathol 2015;46(11):1776-84.

[29] Zhu YY, Si W, Ji TF, et al. The variation and clinical significance of hormone receptors and Her-2 status from primary to metastatic lesions in breast cancer patients. Tumor Biol 2016;37(6):7675-84.

[30] Mirtavoos-Mahyari H, Khosravi A, Esfahani-Monfared Z. Human epidermal growth factor receptor 2 and estrogen receptor status in respect to tumor characteristics in non-metastatic breast cancer. Tanaffos 2014;13(1):26-34. 